\title{
Survival of Enteric Pathogens During Butterhead Lettuce Growth: Crop Stage, Leaf Age, and Irrigation
}

\author{
Inge Van der Linden,,2 Bart Cottyn, ${ }^{1}$ Mieke Uyttendaele, ${ }^{3}$ Geertrui Vlaemynck, \\ Marc Heyndrickx, ${ }^{1,4}$ and Martine Maes ${ }^{2}$
}

\begin{abstract}
The survival of Salmonella enterica serovar Thompson and Escherichia coli O157 was investigated on growing butterhead lettuce plants in the plant-growth chamber and greenhouse. All inoculation tests were made under conditions that approximate the greenhouse conditions for butterhead lettuce cultivation in Flanders (Belgium). The survival and proliferation of the pathogens on the leaves was determined at days 0,4 , and 8 after inoculation using standard plating techniques on selective medium. In the growth chamber, the extent to which both pathogens were able to multiply on the lettuce leaves was influenced by crop stage and leaf age. On young plants, the older leaves supported pathogen survival better. On nearly mature plants, pathogen population sizes were significantly higher on the old and young leaves compared with middle-aged leaves $(p<0.001)$. In the greenhouse, the environmental regimen with high fluctuations in temperature and relative humidity was less conducive to the survival of $E$. coli O157, though its survival on nearly mature lettuce was enhanced by overhead irrigation. The moist conditions between the folded inner leaves are likely contributing to the survival of enteric pathogens in the lettuce head. Butterhead lettuce grown in greenhouses with a sprinkle irrigation system may present a potential health hazard when contaminated near harvest. Experimental design (growth chamber versus greenhouse) largely influences enteric pathogen behavior on growing lettuce plants.
\end{abstract}

\section{Introduction}

G OVERNMENTS PROMOTE the consumption of fruits and vegetables, but at the same time concerns have been raised about the food safety of leafy vegetables. Leafy vegetables, such as lettuce, are considered by the U.S. Food and Drug Administration as high-risk food (Klein et al., 2009). In Europe as well, various E. coli O157 (Welinder-Olsson et al., 2004; Friesema et al., 2008; Söderström et al., 2008) and Salmonella outbreaks (Ward et al., 2002; Horby et al., 2003; Nygård et al., 2008) have been related to the consumption of lettuce.

Plant surfaces may become contaminated before harvest. Irrigation water is considered a potentially important introduction route, and several studies have shown its potential for the transmission of enteric pathogens to lettuce plants. However, most of these studies were conducted either under laboratory or controlled conditions in growth chambers
(Brandl and Mandrell, 2002; Solomon et al., 2003; Aruscavage et al., 2008; Aruscavage et al., 2010; Brandl and Amundson, 2008; Zhang et al., 2009; Erickson et al., 2010a) or field experiments (Barker-Reid et al., 2009; Erickson et al., 2010b; Harapas et al., 2010; Wood et al., 2010; Fonseca et al., 2011). Few studies have compared both types of experimental setups. Furthermore, these experiments were often performed with lettuce cultivars and environmental conditions typical for the production of leafy vegetables in the United States.

This study focused on butterhead lettuce (Lactuca sativa L. var. capitata), an important leafy vegetable grown commercially in Northern European countries and regions such as Flanders (Belgium) mainly for export. The crop is cultivated in greenhouses in a continuous monoculture system using an overhead sprinkler irrigation (Pauwelyn et al., 2011), creating conditions that, in case of contaminated irrigation water, are likely to deposit enteric pathogens on the lettuce plants. No

\footnotetext{
${ }^{1}$ Technology and Food Science Unit-Food Safety, Institute for Agricultural and Fisheries Research (ILVO), Melle, Belgium.

${ }^{2}$ Plant Sciences Unit-Crop Protection, Institute for Agricultural and Fisheries Research (ILVO), Merelbeke, Belgium.

${ }^{3}$ Department of Food Safety and Food Quality, Laboratory of Food Microbiology and Food Preservation, Ghent University (UGent), Ghent, Belgium.

${ }^{4}$ Department of Pathology, Bacteriology, and Poultry Diseases, Faculty of Veterinary Sciences, Ghent University (UGent), Merelbeke, Belgium.
} 
scientific information is available concerning enteric pathogens for this lettuce cultivar in combination with its commercial growing conditions. The aim of this study was to investigate the effects of leaf age (young, middle-aged, and old), crop stage (before or after heading), and daily overhead irrigation on the survival of E. coli O157:H7 and Salmonella enterica should they be introduced by irrigation water on butterhead lettuce in Northern European greenhouses.

\section{Materials and Methods}

\section{Strains and growth conditions}

Salmonella Thompson RM1987N is a spontaneous nalidixicacid-resistant mutant of a described clinical isolate from a patient in a cilantro-linked outbreak (Brandl et al., 2005) and was kindly donated by Dr. Maria Brandl (USDA-ARS, Albany, CA). E. coli O157:H7 MB3885 naturally lacks Shiga toxin genes (stx1 and stx2) and was used as a nontoxigenic surrogate strain for the Shiga toxin-producing serotype O157:H7 for biosafety reasons. This strain originates from beef carpaccio and was kindly donated by the Scientific Institute for Public Health (Brussels, Belgium). The absence of st $x 1$ and st $x 2$ genes and presence of other virulence genes eae (intimin), ehx (enterohemolysin), espP (extracellular serine protease), and katP (catalase-peroxidase) were confirmed by conventional PCR (Verstraete et al., 2012). Both strains were streaked from a glycerol frozen stock maintained at $-70^{\circ} \mathrm{C}$ onto a tryptone soy agar plate (TSA; Oxoid, Basingstoke, UK) and incubated at $37^{\circ} \mathrm{C}$ for $24 \mathrm{~h}$. One colony was transferred to $10 \mathrm{~mL}$ of tryptone soy broth (TSB; Oxoid) and incubated at $37^{\circ} \mathrm{C}$ for $18 \mathrm{~h}$ while shaken at $200 \mathrm{rpm}$.

\section{Plant growth conditions}

Pelletized butterhead lettuce seeds (Lactuca sativa L. var capitata "Alexandria") were obtained from Rijk Zwaan Distribution B.V., De Lier, the Netherlands. The seeds were sown in ground blocks of $4 \times 4 \times 6 \mathrm{~cm}$ (seed and cutting compost, Saniflor, Geraardsbergen, Belgium). Two weeks after sowing, the seedlings were placed in pots of $13-\mathrm{cm}$ (for the experiments with young plants, nine-leaf stage) or 20-cm diameter (for the experiments with nearly mature plants) and grown in the greenhouse at Institute for Agricultural and Fisheries Research (ILVO). For inoculations in the growth chamber, the plants were moved from the greenhouse to the growth chamber (Isocab, Harelbeke, Belgium) 2 days before inoculation and placed in trays with $\pm 2-\mathrm{cm}$ irrigation water. Growth chamber conditions were set at $\pm 19^{\circ} \mathrm{C}$ during the day and at $\pm 12^{\circ} \mathrm{C}$ at night with a relative humidity $(\mathrm{RH})$ of $70-80 \%$ and a photoperiod of $14 \mathrm{~h}$. The greenhouse experiment was conducted in April 2010, and conditions of RH and temperature were logged in 5-min intervals using an EL-USB-2 data logger (Lascar Electronics, Salisbury, UK) (Table 1).

\section{Plant inoculations and irrigation}

Cells of each strain were washed twice by centrifugation $(6000 \times \mathrm{g}, 15 \mathrm{~min})$ in $50 \mathrm{mM}$ phosphate buffered saline (PBS, $\mathrm{pH}$ 7.4). The optical density (OD) was measured at $595 \mathrm{~nm}$ using a microplate reader (Bio-Rad 3550, Richmond, CA) and by using an OD-colony-forming unit (CFU)/mL standard curve, the appropriate amount of cells was resuspended in PBS to give $1 \times 10^{5} \mathrm{CFU} / \mathrm{mL}$. For each combination of pathogen and crop stage, a total of 14 plants were inoculated. Young plants were inoculated by immersion as described by Brandl and Amundson (2008). Nearly mature plants were spray-inoculated as immersion was not feasible for biosafety reasons. The leaves were sprayed with a hand-held sprayer until runoff, which corresponded with approximately $100 \mathrm{~mL}$ inoculum per plant. A preliminary test was performed to compare both inoculation methods. This test showed similar survival trends of the pathogens. The pots were wrapped with plastic film (Saran Wrap; Dow Chemical Company) to prevent soil contamination by dripping. Both inoculation methods resulted in a pathogen level of approximately $3 \times 10^{3}-10^{4} \mathrm{CFU}$ per gram of leaf tissue as determined by selective plating as described hereafter. The control treatment (six plants) consisted of PBS without added inoculum. To test the influence of overhead irrigation, half of the plants in each experiment were also watered from above with a hand-held sprayer until runoff, whereas the other plants were only watered from below. For all experiments, irrigation water from the experimental greenhouse at ILVO was used, which originates from ground water. A chemical analysis of the water was performed by Inagro (Rumbeke-Beitem, Belgium) and ILVO (Merelbeke, Belgium) (Table 2).

\section{Measurement of pathogen populations on lettuce leaves}

Before inoculation, the leaves of young plants were labeled from old to young with small pieces of tape. Old, middle-aged, and young leaves were numbered 1-3, 4-6, and 7-9, respectively. For inoculated nearly mature lettuce heads, the fourth to sixth leaves were sampled as old leaves, the $12^{\text {th }}$ to $14^{\text {th }}$ leaves as middle-aged, and the leaves enclosed in the head as young leaves. Three randomly chosen plants from each treatment (i.e.,

Table 1. Daily Environmental Conditions During Inoculation Experiments in the Controlled EnVironment Growth Chamber AND IN The Greenhouse

\begin{tabular}{|c|c|c|c|c|c|c|c|}
\hline \multirow[b]{2}{*}{ Experiment } & \multirow[b]{2}{*}{ Day/night } & \multicolumn{3}{|c|}{ Temperature $\left({ }^{\circ} \mathrm{C}\right)$} & \multicolumn{3}{|c|}{ Relative humidity (\%) } \\
\hline & & Mean $\pm S D$ & Min. & Max. & Mean $\pm S D$ & Min. & Max. \\
\hline \multirow[t]{2}{*}{ Growth chamber-young plants } & Day & $18.5 \pm 1.1$ & 14.0 & 21.5 & $81.4 \pm 6.0$ & 64.5 & 93.0 \\
\hline & Night & $12.0 \pm 0.9$ & 11.0 & 18.0 & $78.0 \pm 6.9$ & 49.0 & 89.0 \\
\hline \multirow[t]{2}{*}{ Growth chamber-mature plants } & Day & $19.6 \pm 0.7$ & 15.5 & 22.0 & $69.9 \pm 2.8$ & 55.5 & 80.0 \\
\hline & Night & $12.2 \pm 0.9$ & 11.0 & 16.5 & $70.7 \pm 2.9$ & 56.5 & 82.0 \\
\hline \multirow[t]{2}{*}{ Greenhouse-mature plants } & Day & $21.1 \pm 6.0$ & 7.0 & 35.0 & $45.2 \pm 14.4$ & 20.0 & 75.5 \\
\hline & Night & $11.9 \pm 2.4$ & 7.0 & 21.0 & $65.9 \pm 6.6$ & 37.0 & 76.5 \\
\hline
\end{tabular}

$\mathrm{SD}$, standard deviation. 
Table 2. Water Characteristics of the Irrigation Water Used for the Daily Overhead Irrigation Treatment

\begin{tabular}{ccccccccccccccc}
\hline & $\mathrm{EC}$ & $\mathrm{BOD}$ & $\mathrm{COD}$ & $\mathrm{NO}_{3}^{-}$ & $\mathrm{NH}_{4}^{-}$ & $\mathrm{SO}_{4}$ & $\mathrm{Cl}$ & $\mathrm{Fe}$ & $\mathrm{Mn}$ & $\mathrm{Mg}$ & $\mathrm{Ca}$ & $\mathrm{K}$ & $\mathrm{Na}$ \\
\cline { 2 - 5 } & $\mu \mathrm{S} / \mathrm{cm}$ & $m g / L \mathrm{O}_{2}$ & $m g / L \mathrm{O}_{2}$ & $m g / L$ & $m g / L$ & $m g / L$ & $m g / L$ & $\mu g / L$ & $\mu g / L$ & $m g / L$ & $m g / L$ & $m g / L$ & $m g / L$ \\
\hline 7.46 & 637 & $<5.0$ & $<25.0$ & $<5.0$ & $<5.0$ & 462 & 148.8 & 20.0 & 40.0 & 15.1 & 109.2 & 8.6 & 18.4 \\
\hline
\end{tabular}

EC, electrical conductivity; BOD, biological oxygen demand; COD, chemical oxygen demand.

pathogen-crop stage-irrigation combination) were sampled at 4 and 8 days after inoculation, while one plant per treatment was sampled at day 0 . From each plant, three leaves from each leaf age category were collected using sterile instruments. The leaves were cut approximately $1 \mathrm{~cm}$ above the soil surface, placed individually in a sterile extraction bag with filter (Bioreba, Reinach, Switzerland), and each leaf was weighed. Then, PBS with $0.05 \%$ vol/vol Tween 20 was added at a $1 / 1$ (wt/vol) ratio and the sample was ground for $\pm 15 \mathrm{~s}$ at maximum speed (Homex 6, Bioreba) until a homogenous mixture was obtained. Tenfold dilutions of the resulting suspension were made in $0.1 \%$ peptone and spread-plated on xylose lysine desoxycholate (XLD, LAB032; Lab M, Bury, UK) overlaid with TSA for Salmonella (XLD-TAL) or cefixime-tellurite sorbitol
Mac Conkey (CT-SMAC, Lab 161; Lab M, Bury, UK) overlaid with TSA (CT-SMAC-TAL). The TAL method was described earlier for the resuscitation of injured cells (Kang and Fung, 2000; Qiu and $\mathrm{Wu}, 2007)$. All plates were incubated at $37^{\circ} \mathrm{C}$ for at least $18 \mathrm{~h}$. Simultaneously, a nonselective enrichment was conducted by adding $1 \mathrm{~mL}$ of leaf homogenate to $9 \mathrm{~mL}$ of buffered peptone water (Oxoid) and incubated at $37^{\circ} \mathrm{C}, 200 \mathrm{rpm}$ for $24 \mathrm{~h}$. Only when the plate counts were below the detection limit $(<1.3 \log \mathrm{CFU} / \mathrm{g})$, $100 \mu \mathrm{L}$ of the enrichment culture was streaked onto the appropriate selective medium.

Two different controls were performed to ensure that the inoculated strains and not the indigenous bacteria were counted. First, the undiluted leaf homogenate of the control plants

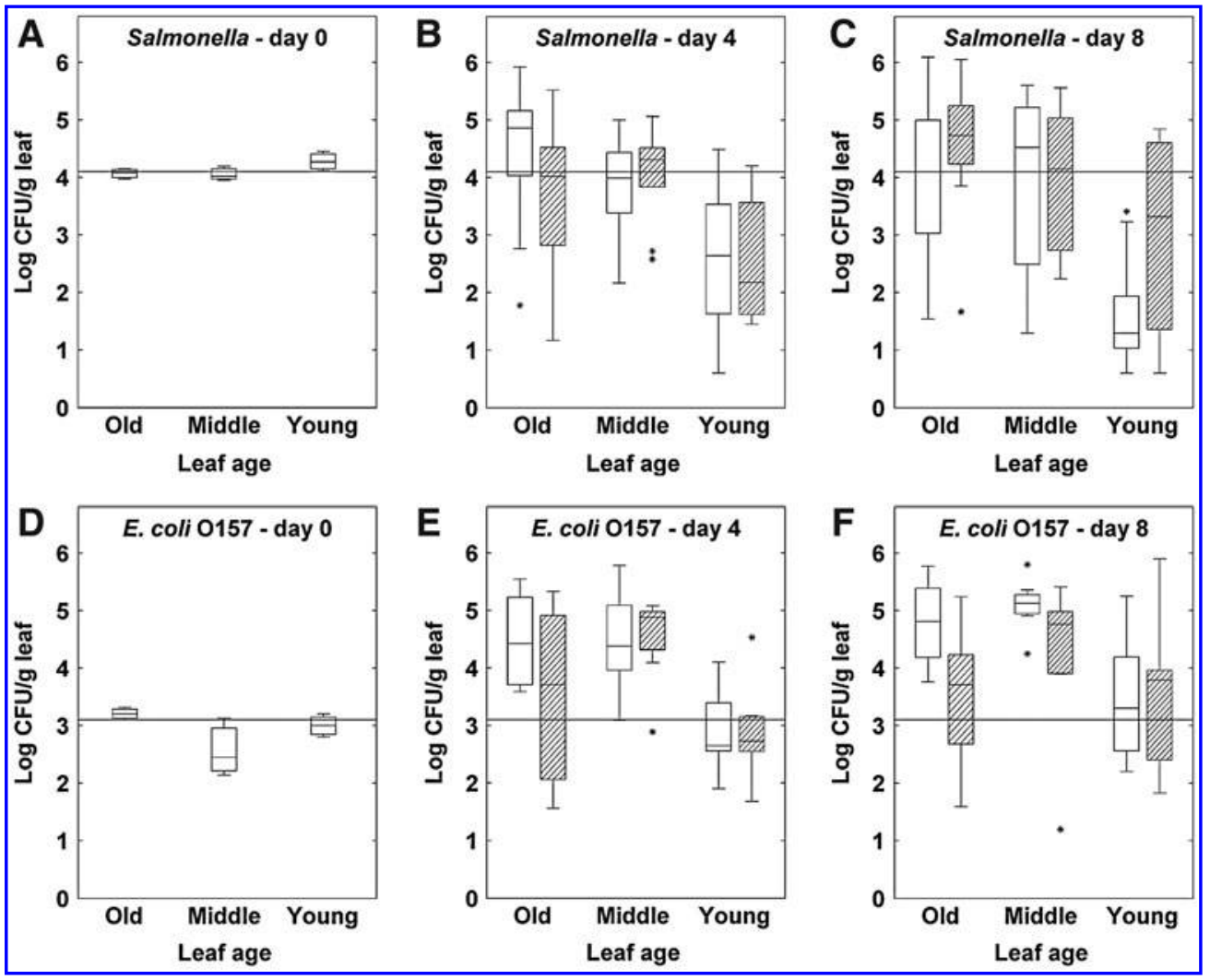

FIG. 1. Growth chamber experiment with young butterhead lettuce (nine-leaf stage): pathogen population dynamics on young, middle-aged, and old leaves at 0,4 , and 8 days after inoculation. (A-C) Population dynamics of Salmonella enterica serovar Thompson strain RM1987N. (D-F) Population dynamics of Escherichia coli O157:H7 strain MB3885. Data are presented as box plots. The non-overhead-irrigated plants are represented by white bars; the overhead-irrigated plants are represented by hatched bars. At day 0 , no distinction between overhead irrigated and non-overhead-irrigated plants was made. The bottom and top of the box are the $25^{\text {th }}$ and $75^{\text {th }}$ percentile. The line in the box is the median and the end of the whiskers are the minimum and maximum of the data, which are not outliers or extremes. Outliers and extremes are represented with an asterisk. The data are calculated from the log-transformed values of the pathogen population size per gram tissue of six leaf samples at day 0 and nine leaf samples at days 4 and 8 . The horizontal line shows the median of the pathogen counts at day 0 . CFU, colony-forming units. 
was plated onto XLD-TAL and/or CT-SMAC-TAL. Second, randomly selected and presumptive nonpathogen colonies were subjected to a serological test (E. coli O157:H7: DR0620, Oxoid, Basingstoke; Salmonella: DR1108, Oxoid, Basingstoke).

\section{Statistical analyses}

The data were analyzed in SPSS (IBM SPSS Statistics 19) using a multi-factor analysis of variance (linear models) with $\alpha=0.05$. The data were normalized by subtracting the mean of the log count at day 0 from the mean of the log-transformed values at days 4 and 8 . The explanatory fixed variables were day (day 4 or day 8), leaf age (young-middle-aged-old) and overhead irrigation treatment (with or without). Full factorial design was first performed. If all the interaction terms were not significant, a simplified model without interaction could be used with the Scheffé-test as post-hoc test. In other instances, Fisher's Least Significant Difference post-hoc comparisons were made with the combinations of the groups. Values below the detection limit were considered to be at the detection limit $(1.3 \log \mathrm{CFU} / \mathrm{g})$ if the enrichment was positive, whereas those testing negative by enrichment culture were assigned a value of 0.0 as described by Erickson et al. (2010a).

\section{Results}

\section{Survival and growth potential on young plants} in the growth chamber

The results are shown in Figure 1. Both pathogens were able to proliferate on lettuce leaves after inoculation. For Salmonella, no significant differences were found between the average counts at 4 and 8 days after inoculation $(p>0.05)$, whereas for E. coli $\mathrm{O} 157$ a slight increase could be observed $(0.01<p<0.05)$. For both pathogens, no significant differences were identified between plants with and without daily overhead irrigation, and survival on the youngest leaves was significantly lower than on the middle-aged or oldest leaves $(p<0.001)$. For Salmonella (Fig. 1A-C), the viable counts decreased by $1.14 \log \mathrm{CFU} / \mathrm{g}$ on the young leaves, whereas they slightly increased on the middle-aged and old leaves by 0.38 and $0.54 \log \mathrm{CFU} / \mathrm{g}$, respectively (average of days 4 and 8). For E. coli O157 (Fig. 1D-F), the same trend was observed but with a greater relative increase. On average, the E. coli $\mathrm{O} 157$ counts on the young leaves increased slightly $(0.40 \log \mathrm{CFU} / \mathrm{g})$ and showed a greater increase on the middle-aged and old leaves (1.86 and $1.99 \log \mathrm{CFU} / \mathrm{g}$, respectively). At day 8, however, this leaf age effect was no longer measurable for the

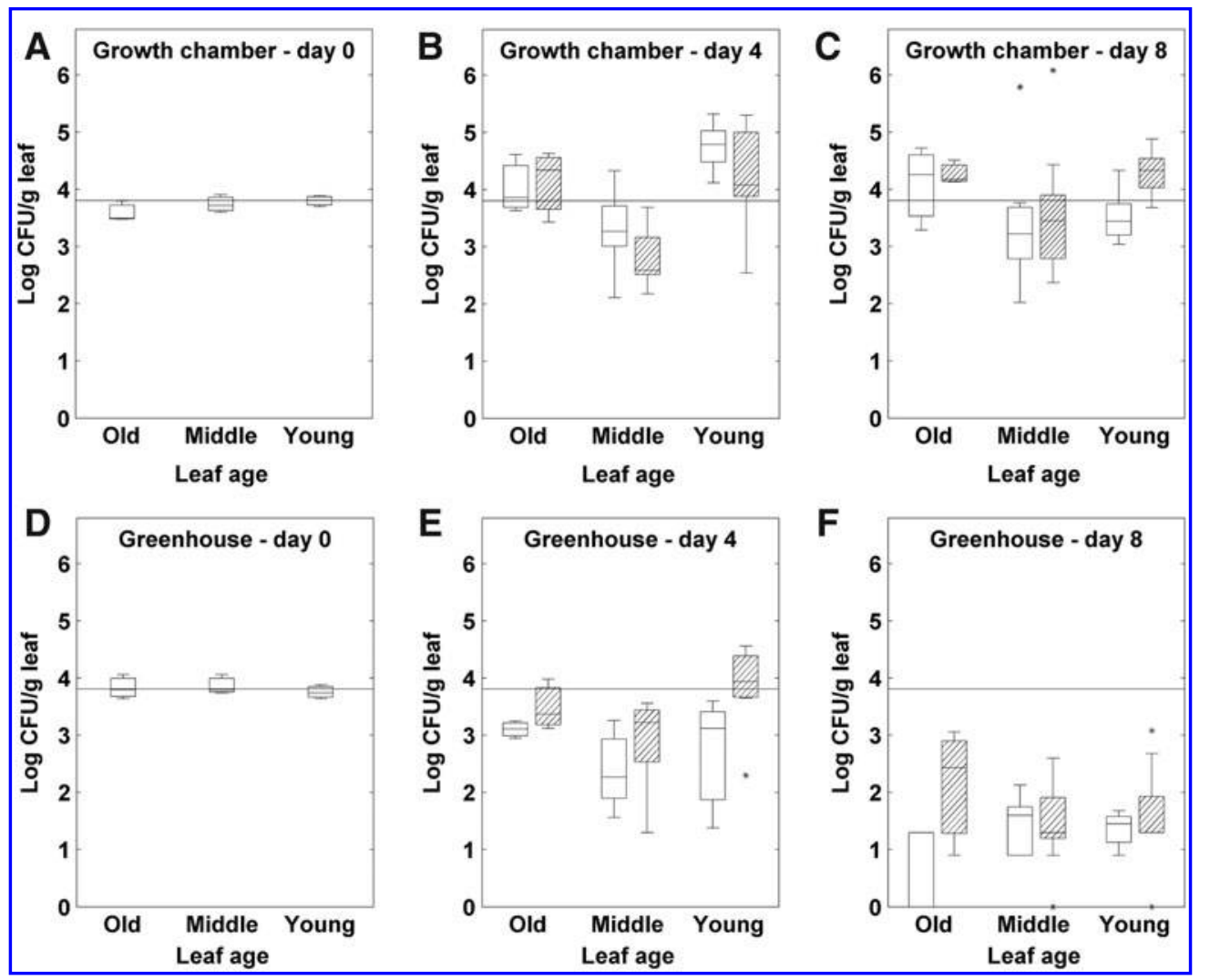

FIG. 2. Preharvest population dynamics of Escherichia coli O157:H7 strain MB3885 on young, middle-aged, and old leaves of nearly mature butterhead lettuce plants at 0,4 , and 8 days after inoculation in the growth chamber and in the greenhouse. (A-C) Results from the growth chamber experiment. (D-F) Results from the greenhouse experiment. Data are presented as box plots. The non-overhead-irrigated plants are represented by white bars; the overhead-irrigated plants are represented by hatched bars. At day 0, no distinction between overhead irrigated and non-overhead-irrigated plants was made. The bottom and top of the box are the $25^{\text {th }}$ and $75^{\text {th }}$ percentile. The line in the box is the median and the end of the whiskers is the minimum and maximum of the data that are not outliers or extremes. Outliers and extremes are represented with an asterisk. The data are calculated from the log-transformed values of the pathogen population size per gram tissue of six leaf samples at day 0 and nine leaf samples at days 4 and 8. The horizontal line shows the median of the pathogen counts at day 0 . CFU, colony-forming units. 
daily irrigated plants inoculated with E. coli O157 (Fig. 1F). Generally, the pathogen population sizes greatly varied from one leaf to another, even between leaves of the same leaf age class.

\section{Survival and growth potential on nearly mature plants in the growth chamber}

The results are shown in Figure 2A-C. Leaf age had a significant effect $(p<0.001)$ and overhead irrigation had no effect. Leaf age did not have the same effect for nearly mature plants as compared to the young plants: E. coli O157 proliferated on young inner leaves and oldest outer leaves (an average increase of 0.67 and $0.28 \mathrm{log} \mathrm{CFU} / \mathrm{g}$, respectively) and decreased on the middle-aged lettuce leaves (on average $-0.76 \log \mathrm{CFU} / \mathrm{g}$ ). This leaf age effect was most obvious on day 4 and was no longer observed on day 8 after inoculation. On average, the total number of pathogens per plant did not increase significantly during the 8 days in the growth chamber. Similar trends were also observed for Salmonella, though this experiment was only conducted until day 4 (see Supplementary Fig. S1) (Supplementary Data are available online at www.liebertpub.com/fpd).

\section{Survival and growth potential on nearly mature lettuce in the greenhouse}

The results are shown in Figure 2D-F. On average, no increase in pathogen counts was observed, and the survival of E. coli $\mathrm{O} 157$ was significantly lower than in the experiment conducted in the growth chamber. On day 4, E. coli O157 survived the best (initial inoculum density was retained) on young, overhead-irrigated leaves $(p<0.01)$. Only at day 4 , a leaf age effect existed between young and middle-aged leaves of the overhead-irrigated plants. On day 8, the E. coli O157 level was significantly higher on old leaves of overhead-irrigated plants, whereas an enrichment step was needed to detect the pathogen on old leaves of nonirrigated heads $(0.01<p<0.05)$. On the middle-aged leaves, no statistically significant influence of overhead irrigation was observed. The average number of $E$. coli $\mathrm{O} 157$ had decreased to $1.54 \pm 0.88 \log \mathrm{CFU} / \mathrm{g}$ for the daily overhead-irrigated plants, and to $1.38 \pm 0.38 \log \mathrm{CFU} / \mathrm{g}$ leaf for the nonirrigated plants. In total, 13 of the 54 samples had to be enriched but in 10 of these 13 samples, the pathogen could still be detected. This experiment could not be performed for Salmonella for biosafety reasons.

\section{Discussion}

In the present study, we looked at plant-related factors such as leaf age, crop stage, and overhead irrigation to see whether these can have a potential influence on the survival of enteric pathogens in the phyllosphere of lettuce. In comparison with other studies on the survival of these pathogens on fresh produce (e.g., Aruscavage et al., 2008; Brandl and Amundson, 2008; Erickson et al., 2010a), we used growing butterhead lettuce plants cultivated under realistic northern European lettuce production conditions. The experiments were performed under the controlled conditions of a growth chamber, but in parallel an experiment in the greenhouse was made to evaluate whether the investigated factors are also important under conditions of current practice.
The experiments in the growth chamber revealed that lettuce leaf age in combination with crop stage has an effect on the survival capacity of the pathogen. The first evidence for this phenomenon was presented by Brandl and Amundson (2008). The experimental design of our growth chamber study was quite similar to theirs, but differed in the used lettuce cultivar (butterhead lettuce with softer folded leaves and closed head formation versus romaine lettuce with upright long leaves and semi-open head formation), lower temperatures $\left(19^{\circ} \mathrm{C}\right.$ day $-12^{\circ} \mathrm{C}$ night versus constantly $\left.28^{\circ} \mathrm{C}\right)$, lower $\mathrm{RH}$ ( $70-80 \%$ versus $100 \%$ ) and longer sampling period (8 days versus $2-3$ days). For nearly mature plants, the pathogen population dynamics on the leaves at day 4 after inoculation were in agreement with their findings. The highest population size of E. coli $\mathrm{O} 157$ found on the young inner leaves, which are preferably consumed, was on average $1.4 \log \mathrm{CFU} / \mathrm{g}$ higher than on the middle-aged leaves. However, at day 8 after inoculation, when the plants were ready for harvest, this youngleaf effect was no longer observed. Brandl and Amundson (2008) reported a similar young-leaf effect for young plants as well as for nearly mature plants. In contrast, the population size of the pathogens on young plants in our study was on average $1.60 \log \mathrm{CFU} / \mathrm{g}$ lower compared to the old and middle-aged leaves. Our results do not necessarily contradict the findings of Brandl and Amundson (2008), as we may have missed the young-leaf effect on young plants because of our later sampling of day 4 after inoculation. This was also suggested by an additional experiment that included a sampling at day 1 after inoculation whereby growth of the pathogen was noted after 1 day (data not shown). Several factors may explain our different results on young leaves of young plants. During the 8 days in the growth chamber, the young leaves became more mature and the nutrient availability may have changed. Brandl and Amundson ascribed the leaf-agedependent growth to the different nitrogen content in the exudates from leaves of different ages. The bigger relative change in leaf size of young leaves of young plants may also have an effect on the pathogen counts. As an illustration, the average weight of the young leaves increased by $\pm 36 \%$, whereas the old and middle-aged leaves of the young plants did not grow much. Also, it is likely that in contrast to the folded young leaves of nearly mature lettuce, the younger leaves of young plants are more susceptible to desiccation over time because they lack protection from other leaves.

Several authors have highlighted the importance of the $\mathrm{RH}$ conditions for survival of bacterial pathogens on plants (O'Brien and Lindow, 1989; Brandl and Mandrell, 2002; Stine et al., 2005). It was shown that Salmonella could barely grow on plants that were kept below $40-50 \%$ RH but that short periods of high RH were sufficient to recover maximum population size on the leaves (Brandl and Mandrell, 2002). Therefore, we expected that daily overhead irrigation, hence higher humidity, could lead to an increased growth of the pathogens on the leaves. However, in the growth chamber additional daily overhead irrigation on top of the relative high humidity (70$80 \%$ ) had no effect on the behavior of the pathogens. In the greenhouse, the effect of overhead irrigation was only sporadic. The $\mathrm{RH}$ was $45 \%$ on average during the day with higher values up to $76 \%$ measured at night, but this did not seem to be sufficient for resuscitation of E. coli $\mathrm{O} 157$ on the leaves. The plants were irrigated daily in the morning, but after $2 \mathrm{~h}$ most of the water on the leaves was already evaporated; therefore, 
the period of higher relative humidity may not have been long enough. If pathogens are internalized into the leaf tissue, the irrigation treatment may have no effect as well. This could not be investigated because the set-up used for our study did not allow for making a distinction between endo- and epiphytical pathogen populations.

Furthermore, large fluctuations in temperature were measured in the greenhouse. The influence of such fluctuations has not been intensively studied. For natural substrates, Semenov et al. (2007) showed that E. coli O157 and Salmonella inoculated in cow manure were very sensitive to fluctuating temperatures. Future research should be directed to investigate the role of environmental fluctuations on plant-pathogen interactions in order to gain better insights into the fitness of enteric pathogens on plants grown under commercial conditions.

\section{Conclusions}

In this study, it was demonstrated that leaf age, crop stage, and experimental design can have an important influence on the survival and proliferation of E. coli O157 and Salmonella on butterhead lettuce. Greenhouse conditions with high fluctuations in temperature and $\mathrm{RH}$ were less favorable for enteric pathogen growth compared to controlled conditions. The impact of daily overhead irrigation was only observed in the greenhouse on nearly mature plants, indicating that sprinkler irrigation may increase food safety risk, especially after lettuce heading.

\section{Acknowledgments}

We wish to thank Dr. Maria Brandl and the Scientific Institute for Public Health (Brussels, Belgium) for providing strains, Marleen Seynnaeve and Chris Van Waes for analyzing the irrigation water sample, and Cinzia Van Malderghem for excellent technical support. This study was funded by the Federal Public Service of Health, Food Chain Safety and Environment (contract SALCOSLA RF 6202).

\section{Disclosure Statement}

No competing financial interests exist.

\section{References}

Aruscavage D, Miller SA, Ivey MLL, Lee K, LeJeune JT. Survival and dissemination of Escherichia coli O157:H7 on physically and biologically damaged lettuce plants. J Food Prot 2008;71: 2384-2388.

Aruscavage D, Phelan PL, Lee K, LeJeune JT. Impact of changes in sugar exudate created by biological damage to tomato plants on the persistence of Escherichia coli O157:H7. J Food Sci 2010;75:M187-M192.

Barker-Reid F, Harapas D, Engleitner S, Kreidl S, Holmes R, Faggian R. Persistence of Escherichia coli on injured iceberg lettuce in the field, overhead irrigated with contaminated water. J Food Prot 2009;72:458-464.

Brandl MT, Amundson R. Leaf age as a risk factor in contamination of lettuce with Escherichia coli O157:H7 and Salmonella enterica. Appl Environ Microbiol 2008;74:2298-2306.

Brandl MT, Mandrell RE. Fitness of Salmonella enterica serovar Thompson in the cilantro phyllosphere. Appl Environ Microbiol 2002;68:3614-3621.

Brandl MT, Miller WG, Bates AH, Mandrell RE. Production of autoinducer 2 in Salmonella enterica serovar Thompson con- tributes to its fitness in chickens but not on cilantro leaf surfaces. Appl Environ Microbiol 2005;71:2653-2662.

Erickson MC, Liao J, Payton AS, Riley DG, Webb CC, Davey LE, Kimbrel S, Ma L, Zhang G, Flitcroft I, Doyle MP, Beuchat LR. Preharvest internalization of Escherichia coli O157:H7 into lettuce leaves, as affected by insect and physical damage. J Food Prot 2010a;73:1809-1816.

Erickson MC, Webb CC, Diaz-Perez JC, Phatak SC, Silvoy JJ, Davey L, Payton AS, Liao J, Ma L, Doyle MP. Surface and internalized Escherichia coli O157:H7 on field-grown spinach and lettuce treated with spray-contaminated irrigation water. I Food Prot 2010b;73:1023-1029.

Fonseca JM, Fallon SD, Sanchez CA, Nolte KD. Escherichia coli survival in lettuce fields following its introduction through different irrigation systems. I Appl Microbiol 2011;110:893902.

Friesema I, Sigmundsdottir G, van der Zwaluw K, Heuvelink A, Schimmer B, de Jager C, Rump B, Briem H, Hardardottir H, Atladottir A, Gudmundsdottir E, van Pelt W. An international outbreak of Shiga toxin-producing Escherichia coli O157 infection due to lettuce, September-October 2007. Euro Surveill 2008;13:19065.

Harapas D, Premier R, Tomkins B, Franz P, Ajlouni S. Persistence of Escherichia coli on injured vegetable plants. Int J Food Microbiol 2010;138:232-237.

Horby PW, O'Brien SJ, Adak GK, Graham C, Hawker JI, Hunter P, Lane C, Lawson AJ, Mitchell RT, Reacher MH, Threlfall EJ, Ward LR. A national outbreak of multi-resistant Salmonella enterica serovar Typhimurium definitive phage type (DT) 104 associated with consumption of lettuce. Epidemiol Infect 2003;130:169-178.

Kang DH, Fung DYC. Application of thin agar layer method for recovery of injured Salmonella Typhimurium. Int J Food Microbiol 2000;54:127-132.

Klein S, Tian A, Witmer J, DeWaal CS. The FDA Top Ten: The Riskiest Foods Regulated by the US Food and Drug Administration. Washington, DC: The Center for Science in the Public Interest, 2009.

Nygård K, Lassen J, Vold L, Andersson Y, Fisher I, Löfdahl S, Threlfall J, Luzzi I, Peters T, Hampton M, Torpdahl M, Kapperud G, Aavitsland P. Outbreak of Salmonella Thompson infections linked to imported rucola lettuce. Foodborne Pathog Dis 2008;5:165-173.

O'Brien RD, Lindow SE. Effect of plant species and environmental conditions on epiphytic population sizes of Pseudomonas syringae and other bacteria. Phytopathology 1989;79: 619-627.

Pauwelyn E, Vanhouteghem K, Cottyn B, De Vos P, Maes M, Bleyaert P, Höfte M. Epidemiology of Pseudomonas cichorii, the cause of lettuce midrib rot. J Phytopathol 2011;159:298-305.

Qiu X, Wu VCH. Evaluation of Escherichia coli O157:H7, Listeria monocytogenes, Salmonella typhimurium and Staphylococcus areus in ground beef with cranberry concentrate by thin agar layer method. J Rapid Methods Autom Microbiol 2007;15:282-294.

Semenov AV, van Bruggen AHC, Van Overbeek L, Termorshuizen AJ, Semenov AM. Influence of temperature fluctuations on Escherichia coli O157:H7 and Salmonella enterica serovar Typhimurium in cow manure. Fems Microbiol Ecol 2007;60:419-428.

Söderström A, Österberg P, Lindqvist A, Jönsson B, Lindberg A, Blide Ulander S, Welinder-Olsson C, Löfdahl S, Kaijser B, De Jong B, Kühlmann-Berenzon S, Boqvist S, Eriksson E, Szanto E, Andersson S, Allestam G, Hedenström I, Ledet Muller L, Andersson Y. A large Escherichia coli O157 outbreak in Sweden 
associated with locally produced lettuce. Foodborne Pathog Dis 2008;5:339-349.

Solomon EB, Pang HJ, Matthews KR. Persistence of Escherichia coli O157:H7 on lettuce plants following spray irrigation with contaminated water. I Food Prot 2003;66:2198-2202.

Stine SW, Song I, Choi CY, Gerba CP. Effect of relative humidity on preharvest survival of bacterial and viral pathogens on the surface of cantaloupe, lettuce, and bell peppers. I Food Prot 2005;68:1352-1358.

Verstraete K, De Reu K, Van Weyenberg S, Piérard D, De Zutter L, Herman L, Robyn J, Heyndrickx M. Genetic characteristics of Shiga toxin producing E. coli O157, O26, O103, O111 and O145 isolates from humans, food, and cattle in Belgium. Epidemiol Infect 2013; in press, available on CJ02013. doi: $10.1017 /$ S0950268813000307.

Ward LR, Maguire C, Hampton MD, de Pinna E, Smith HR, Little CL, Gillespie IA, O'Brien SJ, Mitchell RT, Sharp C, Swann RA, Doyle O, Threlfall EJ. Collaborative investigation of an outbreak of Salmonella enterica serotype Newport in England and Wales in 2001 associated with ready-to-eat salad vegetables. Comm Dis Publ Health 2002;5:301-304.

Welinder-Olsson C, Stenqvist K, Badenfors M, Brandberg A, Florén K, Holm M, Holmberg L, Kjellin E, Mårild S, Studahl
A, Kaijser B. EHEC outbreak among staff at a children's hospital-use of PCR for verocytotoxin detection and PFGE for epidemiological investigation. Epidemiol Infect 2004;132: 43-49.

Wood JD, Bezanson GS, Gordon RJ, Jamieson R. Population dynamics of Escherichia coli inoculated by irrigation into the phyllosphere of spinach grown under commercial production conditions. Int J Food Microbiol 2010;143:198-204.

Zhang GD, Ma L, Beuchat LR, Erickson MC, Phelan VH, Doyle MP. Lack of internalization of Escherichia coli O157:H7 in lettuce (Lactuca sativa L.) after leaf surface and soil inoculation. I Food Prot 2009;72:2028-2037.

Address correspondence to:

Bart Cottyn, PhD

Plant Sciences Unit-Crop Protection

Institute for Agricultural and Fisheries Research (ILVO)

B. Van Gansberghelaan 96

B-9820 Merelbeke, Belgium

E-mail: Bart.Cottyn@ilvo.vlaanderen.be 